\title{
Recovery of Oswaldotrema nacinovici from Whimbrels (Aves) in Korea
}

\author{
Young-II Lee', Ok-Sik Chung'², Min Seo ${ }^{3, *}$ \\ ${ }^{1}$ Department of Anatomy, College of Medicine, Dankook University, Cheonan 31116, Korea; ${ }^{2}$ Division of Ecology and Environment, Chungnam \\ Development Institute, Gongju 32589, Korea; ${ }^{3}$ Department of Parasitology and Research Center for Mummy, College of Medicine, Dankook \\ University, Cheonan 31116, Korea
}

\begin{abstract}
Adult specimens of Oswaldotrema nacinovici (Digenea: Philophthalmidae) have been first identified in Korea from 2 migratory birds (whimbrels, Numenius phaeopus) which were found dead at a western seashore area near Gunsan. The worms were recovered in the intestine of these birds. The worms were morphologically characterized by a large ventral sucker in comparison to the oral sucker, an external seminal vesicle extending beyond the posterior margin of the ventral sucker, and conspicuous uterine seminal receptacle. It was noteworthy that metacercariae-like bodies were contained within the inflated regions of 2 ceca. Other intestinal trematode species found in whimbrels included Spelotrema pygmeum, Gynaecotyla squatarolae, Maritrema obstipum, and Himasthla megacotyle. Zoonotic potential of these trematode species should be taken into considerations.
\end{abstract}

Key words: Oswaldotrema nacinovici, whimbrel (Numenius phaeopus), intestinal fluke, parasite fauna, Korea

Studies on trematodes of migratory birds have been performed worldwide for a long time. In the curlew (Numenius americanus) of the Galveston area of Texa Gulfcoast, USA, several species of intestinal trematodes were recovered [1]. In the coast of Belize bordering the Gulf of Mexico, several species of trematodes and cestodes were also collected from the shorebirds [2,3]. Ocular trematodes, such as Philophthalmus gralli (an oriental eye fluke), are known to occur naturally in a wide variety of birds, including struthioniforme [4-7]. Interestingly, Philophthalmus hegeneri which is the only representative of Philophthalmus sp. in Arabia [8], was originally found in the Gulf of Mexico [9]. Generally, among shorebirds, trematodes are dominant in marine birds, whereas cestodes are dominant in freshwater birds. However, cestodes are known to be dominant in certain marine habitats, such as Bristol Bay, Alaska, and Belize, Central America [10,11].

The majority of trematodes are spread by migrating birds, and the seashores of the Korean Peninsula provide proper conditions for these migrating birds to stay. Thus, the trema-

\footnotetext{
- Received 7 November 2016, revised 18 November 2016, accepted 18 November 2016. *Corresponding author (bbbenji@naver.com) (C) 2016, Korean Society for Parasitology and Tropical Medicine This is an Open Access article distributed under the terms of the Creative Commons Attribution Non-Commercial License (http://creativecommons.org/licenses/by-nc/4.0) which permits unrestricted non-commercial use, distribution, and reproduction in any medium, provided the original work is properly cited.
}

todes of birds have already been clinical matters in Korea. Infection with a human trematode, Gymnophalloides seoi, is now recognized as an emerging parasitic disease which makes acute gastrointestinal problems, such as pancreatitis $[12,13]$. Its second intermediate host is the oyster (Crassostrea gigas) [14], and the oystercatcher (Haematopus ostralegus) is known to be a natural definitive host [15]. These seasonal migrating birds usually stay at the western seashores of the Korean Peninsula, while they migrate between Siberian tundra and Australia. Through a nationwide survey, more than 20 endemic areas with a relatively high prevalence of G. seoi infection were located along the coastal villages of the Korean Peninsula [16-18]. Two species of microphallids had also been collected from migratory birds in Korea $[19,20]$, and recently, the presence of Endocotyle and Spelotrema was also reported in Korea [21]. However, considering the number and diversity of migratory birds that stay in the Korean Peninsula, consistent investigations of their parasites seem to be required.

Foreshore soil and environment with plenty of feeds for the wild birds, such as small crabs, shellfishes, and earthworms along the coasts of the Korean Peninsula provide adequate conditions for migratory birds to drop by on their way to the breeding or wintering grounds. Among these birds, Numenius phaeopus (the whimbrel) belongs to the large family Scolopacidae and stay on the coastal regions of the Korean Peninsula in 
Table 1. The kinds and numbers of recovered flukes from 5 whimbrels

\begin{tabular}{|c|c|c|c|c|c|c|}
\hline \multirow{2}{*}{ Name of parasite } & \multicolumn{6}{|c|}{ No. of parasite specimens recovered from each whimbrel (code no.) } \\
\hline & 1 & 2 & 3 & 4 & 5 & Total no. of specimens \\
\hline Spelotrema pygmeum & 27 & 118 & 3 & 361 & 1 & 510 \\
\hline Gynaecotyla squatarolae & 1 & 280 & 0 & 17 & 2 & 300 \\
\hline Maritrema obstipum & 27 & 0 & 0 & 6 & 0 & 33 \\
\hline Oswaldotrema nacinovici & 0 & 23 & 0 & 1 & 0 & 24 \\
\hline
\end{tabular}
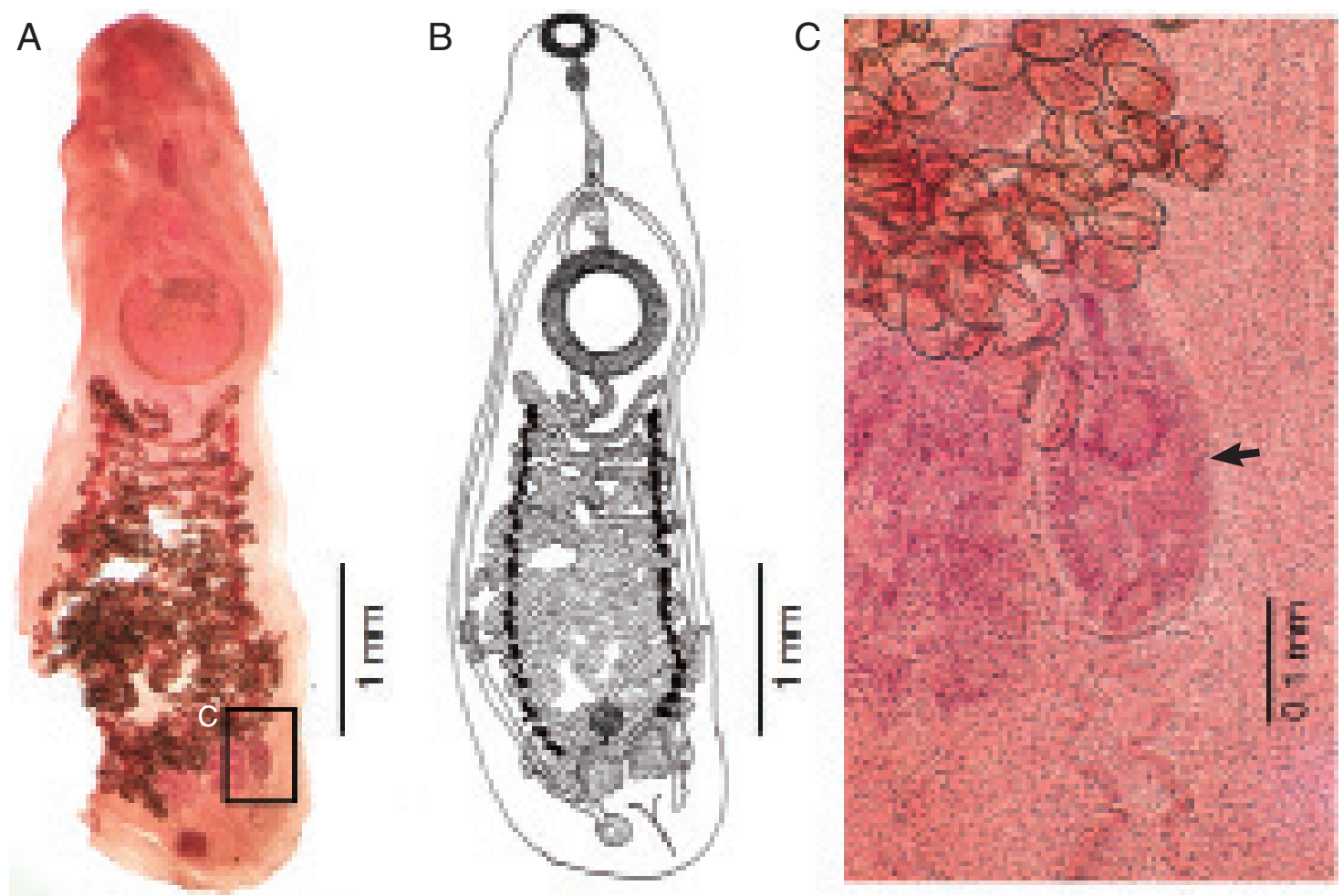

Fig. 1. (A) Adult specimen of Oswaldotrema nacinovici recovered from the intestine of a whimbrel Numenius phaeopus dead on a western seashore of Korea. A large ventral sucker, external seminal vesicle extending beyond the ventral sucker, and ceca containing metacercariae-like bodies are characteristic features of this parasite. (B) Line drawing of the worm in Fig. 1A. (C) A metacercaria-like body (arrow) is seen deep inside (near the terminal portion of) the left cecum.

spring and autumn periods during migration. The present report is to refer Oswaldotrema nacinovici, a new parasite fauna which parasitizes N. phaeopus birds in Korea. This new trematode was originally reported from N. phaeopus in Brazil [22]. However, detailed information on parasites of $N$. phaeopus is still lacking in Brazil because of its migratory habits. Therefore, the infection route of this trematode will be assumed in relation to the case of Brazil. Chances of accidental human infections by this or other related trematodes transmitted by migrating birds will be discussed in this report.

In May 2011, a survey on helminthic infection status among the migrating shorebirds in a western coastal area of Korea was performed. In this survey, 5 whimbrels were found dead at a coastal area of Gunsan-si, Jeollabuk-do. They were immediately transferred to our laboratory, and the intestines were separated. Then, they were opened longitudinally in saline, and the intestinal contents were examined for the presence of parasites. If some trematodes were observed, they were fixed in 10\% neutral formalin, stained with carmine, and their species were identified under light microscopy.

Through these investigations, all the whimbrels were found to be infected with at least more than 1 species of trematodes of 5 different species. They were identified as Spelotrema pygmeum, Gynaecotyla squatarolae, Maritrema obstipum, Himasthla 
Table 2. Comparative measurements of Oswaldotrema nacinovici found in Korea with that reported in Brazil ( $\mu \mathrm{m})$

\begin{tabular}{lcc}
\hline Organ & Korea $^{a}$ & Brazil [22] \\
\hline Body size (length/width; LM) & $7,054 / 2,005$ & $3,710 / 1,229$ \\
Oral sucker (LM) & $297 / 396$ & $280 / 260$ \\
Prepharynx & 25 & 70 \\
Pharynx & 243 & 140 \\
Esophagus & 693 & 530 \\
Ventral sucker (LM) & $891 / 901$ & $670 / 590$ \\
Right testis (LM) & $347 / 297$ & $290 / 340$ \\
Left testis (LM) & $327 / 317$ & $410 / 360$ \\
Egg (uterine) & $75 \times 39(n=10)$ & $65 \times 29(n=5)$ \\
\hline
\end{tabular}

${ }^{a}$ Measurements are based on 1 fully matured adult specimen.

megacotyle, and an unfamiliar species, later identified as $O$. nacinovici (Table 1; Fig. 1A, B). Total 24 specimens of $O$. nacinovici were collected from 2 of the 5 whimbrels examined. Among them, only 1 was fully matured adult (Fig. 1), and the other 23 were juvenile or immature worms. The adult specimen has been deposited in the Department of Parasitology, College of Medicine, Dankook University, Cheonan, Korea (DUPC no. 16-0001).

The morphological characteristics of $O$. nacinovici were as follows (Fig. 1A, B): Body elliptical, oral sucker less than a half of ventral sucker. Prepharynx short. Esophagus long, bifurcating in front of genital pore. External seminal vesicle tubular, extending dorsally and longitudinally beyond acetabulum. Ceca extending nearly to the posterior end with distal inflation; inflated end parts containing metacercariae-like bodies. Testes between the cecal ends. Germarium located just anterior to testes. Cirrus sac not seen. Vitellaria follicular, from ventral sucker to testes level. The size of each organ (based on 1 adult worm) was as listed in Table 2. From these findings, these worms were identified as the adult worms of Oswaldotrema sp.

Trematodes of whimbrels had already been subjects of studies. The specimens diagnosed as O. nacinovici in this study was the same as that reported previously in Brazil [22]. This relatively new genus (Oswaldotrema) is similar or related to genera Pittacium, Cloacitrema, Parorchis, and Pygorchis. In the report from Brazil, it was suggested that the parasitic infections of migrating birds, including the whimbrel, which stay on wintering grounds in Brazil might be related to the migration to breeding grounds of northern hemisphere, such as Siberian tundra or Arctic moorland.

It is known that $N$. phaeopus birds which stay on the Korean Peninsula during migration have different sites as breeding grounds. There are 4 subspecies in N. phaeopus, and the breeding grounds are divided according to their subspecies. Both northeastern Asia and northern North America are breeding grounds of $N$. phaeopus. N. phaeopus feeds in a distinctive and very active way, chasing insects and other mobile preys, such as small crabs by probing soft mud or picking off the surface. Furthermore, the subspecies of $N$. phaeopus that fly to the Korean Peninsula or South America share the breeding grounds between northeastern Asia (tundra) and northern North America (Alaska).

At present, considering that the species of trematodes are the same in both Korea and Brazil, the most possible explanation to the infection route of Oswaldotrema can be from Siberian tundra adjacent to Alaska. Another possible explanation of infection route is from Alaska. Therefore, further comprehensive surveys on the intermediate hosts in both subarctic areas along with the investigations of hosts in wintering grounds are needed to clarify the exact infection route of this parasite.

Oswaldotrema, reported for the first time in Brazil, is rather a newly identified genus, and there has been no report on human or mammalian infection cases so far. However, considering raw-seafood-eating habits among Koreans, investigations of possible human infections should be conducted on a frequent basis. Interestingly, some trematodes can simplify their life cycle by displaying a facultative life-cycle diversification [23]. This situation could be also considered when a host in the life-cycle is unavailable periodically by, for example, seasonal migration. Thus, a sophisticated addition of waiting stages, especially the metacercarial stage may enhance the chances of transmission to a host [24].

In conclusion, the infection route of $O$. nacinovici found in Korea is most probably from northeastern Asia near Alaska by migrating $N$. phaeopus. All the facts and assumes of the present report emphasizes the importance of consecutive studies on avian parasites in relation to possible human infections. Efforts to find out new species of helminths parasitizing the birds should also be continued especially in Korea where a large variety of migratory birds gather around seasonally.

\section{ACKNOWLEDGMENT}

This work was supported by a research fund of Dankook University in 2014. 


\section{CONFLICT OF INTEREST}

We have no conflict of interest related to this work.

\section{REFERENCES}

1. Dronen NO Jr, Badley JE. Helminths of shorebirds from the Texas Gulfcoast. I. Digenetic trematodes from the long-billed curlew, Numenius americanus. J Parasitol 1979; 65: 645-649.

2. Canaris AG, Kinsella JM. Helminth parasites in six species of shorebirds (Charadrii) from the coast of Belize. Mem Inst Oswaldo Cruz 2001; 96: 827-830.

3. Canaris AG, Deblock S. Paramaritremopsis solielangi n. sp. et Microphallus kinsellae n. sp. (Digenea: Microphallidae) parasites de Charadrii (Aves) du Belize (Amerique Centrale). Syst Parasitol 2000; 47: 127-134.

4. Kalantan AMN, Arfin M, Al-Arefi HA, Bobshait HI, Hamada SA, Al-Thawab FH, Shamrani AA. Occurrence of larval Philophthalmus gralli (Mathis and Leger, 1910) in freshwater snail Melanoides tuberculatus (Muller) from Al-Hafuf, Saudi Arabia and its development into adult in various experimental hosts. Parasitol Int 1997; 46: 127-136.

5. Díaz MT, Hernández LE, Bashirullah AK. Experimental life cycle of Philophthalmus gralli (Trematoda: Philophtalmidae) in Venezuela. Rev Biol Trop 2002; 50: 629-641.

6. Mukaratirwa S, Hove T, Cindzi ZM, Maononga DB, Taruvinga M, Matenga E. First report of a field outbreak of the oriental eyefluke, Philophthalmus gralli (Mathis \& Leger 1910), in commercially reared ostriches (Struthio camelus) in Zimbabwe. Onderstepoort J Vet Res 2005; 72: 203-206.

7. Verocai GG, Lopes LN, Burlini L, Correia TR, de Souza CP, Coumendouros K. Ocurrence of Philophthalmus gralli (Trematoda: Philophthalmidae) in farmed ostriches in Brazil. Trop Anim Health Prod 2009; 41: 1241-1242.

8. Abdul-Salam J, Sreelatha BS, Ashkanani H. The eye fluke Philophthalmus hegeneri (Digenea: Philophthalmidae) in Kuwait Bay. Kuwait J Sci Eng 2004; 31: 119-133.

9. Penner LR, Fried B. Philophthalmus hegeneri sp. n. an ocular trematodes from birds. J Parasitol 1963; 49: 974-977.

10. Schmidt GD, Neiland KA. Hymenolepis (Hym.) deblocki sp. n., and records of other helminths from charadriiform birds. Can J Zool 1968; 46: 1037-1040.

11. Canaris AG, Kinsella JM. Helmith communities of three sympatric species of shorebirds (Charadrii) from four summer seasons at Bristol Bay, Alaska. J Parasitol 2007; 93: 485-490.

12. Lee SH, Chai JY, Hong ST. Gymnophalloides seoi n. sp. (Digenea: Gymnophallidae), the first report of human infection by a gymnophallid. J Parasitol 1993; 79: 677-680.

13. Chai JY, Choi MH, Yu JR, Lee SH. Gymnophalloides seoi: a new human intestinal trematode. Trends Parasitol 2003; 19: 109-112.

14. Lee SH, Choi MH, Seo M, Chai JY. Oysters, Crasostrea gigas, as the second intermediate host of Gymnophalloides seoi (Gymnophallidae). Korean J Parasitol 1995; 33: 1-7.

15. Ryang YS, Yoo JC, Lee SH, Chai JY. The palearctic oystercatcher Haematopus ostralegus, a natural definitive host for Gymnophalloides seoi. J Parasitol 2000; 86: 418-419.

16. Lee SH, Chai JY, Lee HJ, Hong ST, Yu JR, Sohn WM, Kho WG, Choi MH, Lim YJ. High prevalence of Gymnophalloides seoi infection in a village on a southwestern island of the Republic of Korea. Am J Trop Med Hyg 1994; 51: 281-285.

17. Chai JY, Park JH, Han ET, Shin EH, Kim JL, Hong KS, Rim HJ, Lee SH. A nationwide survey of the prevalence of human Gymnophalloides seoi infection on western and southern coastal islands in the Republic of Korea. Korean J Parasitol 2001; 39: 23 30.

18. Guk SM, Park JH, Shin EH, Kim JL, Lin A, Chai JY. Prevalence of Gymnophalloides seoi infection in coastal villages of Haenam-gun and Yeongam-gun, Republic of Korea. Korean J Parasitol 2006; 44: 1-5.

19. Seo M, Guk SM, Chai JY. The ruddy turnstone, Arenaria interpres interpres, a new definitive host for Gynaecotyla squatarolae (Digenea: Microphallidae). Korean J Parasitol 2008; 46: 41-43.

20. Chung OS, Sohn WM, Chai JY, Seo M, Lee HJ. Discovery of Maritrema obstipum (Digenea: Microphallidae) from migratory birds in Korea. Korean J Parasitol 2011; 49: 457-460.

21. Yoo HJ, Chung OS, Seo M. Discovery of Endocotyle incana and Spelotrema pseudogonotyla (Digenea: Microphallidae) from scolopacid migratory birds in Korea. Korean J Parasitol 2012; 50: 273-276.

22. Muniz-Pereira LC, Pinto RM. Oswaldotrema nacinovici gen. nov. sp. nov. (Digenea: Philophthalmidae) from Numenius phaeopus (Aves: Scolopacidae) in Brazil. Mem Inst Oswaldo Cruz 2000; 95: 301-304.

23. Hassl AR. A case of a facultative life-cycle diversification in the fluke Pleurogenoides sp. (Lecithodendriidae, Plagiorchiida). Wien Klin Wochenschr 2010; 122 (suppl): 91-93.

24. Lagrue C, Poulin R. Life cycle abbreviation in trematode parasites and the developmental time hypothesis: is the clock ticking? J Evol Biol 2009; 22: 1727-1738. 